\title{
Rational Emotive Behavior Based on Academic Procrastination Prevention Training Programme of Effectiveness
}

\author{
İhsan DÜŞMEZ \\ Giresun Üniversitesi, Eynesil Kamil Nalbant Meslek Yüksekokulu, Giresun-Türkiye,
}

\author{
Yaşar BARUT
}

Ondokuz Mayls Üniversitesi, Eğitim Bilimleri Fakültesi, Samsun-Türkiye,

\begin{tabular}{|c|c|}
\hline Article histo & \multirow{6}{*}{$\begin{array}{l}\text { The research is an experimental study which has experimental and control } \\
\text { groups, and based on pre-test, post-test, monitoring test model. Research } \\
\text { group consists of second and third grade students of Primary School } \\
\text { Education and Psychological Counseling undergraduate programmes in } \\
\text { Giresun University Faculty of Educational Sciences. The research group } \\
\text { was formed among the students whose academic procrastination tendency } \\
\text { is middle or high, by using academic procrastination scale. } 60 \text { students, } \\
\text { whose academic procrastination tendencies are medium and high level, } \\
\text { were identified. } 24 \text { students, who volunteered to participate to the study, } \\
\text { were appointed randomly to the experimental and control groups. } \\
\text { Academic procrastination scale was used to collect data. Scales were } \\
\text { given to experiment and control groups as pre-test. A prevention of } \\
\text { academic procrastination program which developed by the researcher } \\
\text { based on Rational Emotive Behavioral Approach was applied to the } \\
\text { experimental group. Control group was not given any training. After the } \\
\text { training the of experiment group, post-test measurements were taken. } \\
\text { And also } 30 \text { days after the experimental training, follow-up } \\
\text { measurements were taken. Data were analyzed using Analyzis of } \\
\text { Nonparametric. In the result of the applied program, a significant } \\
\text { difference was found in favor of experiment group in academic } \\
\text { procrastination. The results were interpreted in the light of the literature } \\
\text { considering effects of Rational Emotive Behavioral Approach on } \\
\text { academic procrastination. }\end{array}$} \\
\hline & \\
\hline & \\
\hline & \\
\hline & \\
\hline & \\
\hline
\end{tabular}

\section{Introduction}

Academic procrastination, a behaviour known as putting off impending tasks related to academic activities to the last minute such as attending lessons, doing homework, studying exams, is fundamentally a cognitive problem because the people who postpone doing things have irrational beliefs and ideas about their work, working conditions, and results.

As stated by Klein (1971), the term "procrastination" which means the act or habit of putting off or delaying an action or a decision to a later time comes from the Latin word "Procrastinus". "Pro" means "forward" or "forth" and "crastinus" means "of tomorrow"

*Correspondence: ihsan.dusmez@giresun.edu.tr 
(Steel, 2007).

According to Knaus (2011), procrastination is an automated problem situation which occurs as a result of putting off or delaying an action needlessly arising from out of habitual carelessness or laziness. Procrastination begins with a whisper of negative emotion and it continues with a delay in taking an action and with more delay.

Procrastination is classified as situational and chronic. Situational procrastination is divided into two groups: general procrastination and academic procrastination. General procrastination involves delays in one's daily life like not paying the taxes and bills on time, being late to the appointments, postponing a paper which must be ready on Monday to Tuesday or the next day, ignoring buying a gift for a family member or calling him/her.

Academic procrastination is a problem which is seen as the delay in beginning and completion of academic activities in schools such as students' getting prepared for the exams, doing their homework, and completing projects and meetings to be held with the academic adviser. It is really very difficult for individuals who exhibit situational procrastination behaviour to start a project and to complete it after giving a start to it (Dryden, 2000).

The concept of procrastination have been attempted to be explained by many theories. According to psychoanalytic theory, procrastination is a kind of avoidance reaction performed by an individual during the case of conflict. An individual exhibits avoidance behaviour as a defence mechanism of ego about situations which he perceives as a threat. According to Freud, anxiety acts as an impulse, signifying threat to the ego (Freud, 1936).

Psychodynamic theorists have been very much influenced by Freud and they refer to their childhood experiences. Negative relationships with parents in early childhood experiences bring along passive opposition towards parents who are authority figures and this situation in the later years are generalized into other authority figures (Van Der Kolk, 1987).

When we look at social learning theory, procrastination is explained with "self-regulatory model". An individual who is a procrastinator has low self-regulation and self-efficacy beliefs. Perceived self-efficacy plays a pivotal role in this process of self-management because through its impact on cognitive, motivational, decisional, and affective determinants. Moreover, these individuals have a tendency towards pessimism regarding self-criticism and the results of their actions (Bandura, 1986; Bandura et al., 2003).

Procrastination is fundamentally a cognitive problem because the people who delay things have irrational ideas and beliefs about their work, working conditions, and results. The researchers who conducted a study on university students explored the relationship between unrealistic beliefs and academic procrastination behaviour. The results obtained revealed that there was a positive and significant relationship between academic procrastination and irrational beliefs, depression, low self-esteem, and anxiety (Solomon \& Rothblum, 1984).

A study was carried out with university students using structural equation modelling in Turkey. While a negative relationship was found between academic procrastination and studying, academic life satisfaction, and rational beliefs about academic achievement, a positive-oriented relation was revealed between rational beliefs regarding studying and academic satisfaction and academic achievement (Balk1s, 2013). Moreover, it was found in another study conducted on university students with structural equation modelling in Turkey that there was an intermediary role between the students' increasing self-doubt levels and 
their increasing academic procrastination and increasing academic procrastination and decreasing individual achievement and decreasing achievement and decreasing self-respect (Duru \& Balkıs, 2014). Similarly, a meta-analysis study revealed that students' academic procrastination behaviour had a negative effect on academic performance (Kim \& Seo, 2015).

Procrastination is quite a common behaviour. As stated by Ellis (1980), American college students exhibit wild procrastination behaviour at the rate of $95 \%$ (Weinrach, 1980). It was found in a study (Uzun Özer, 2011) conducted in Turkey that 53\% of the high school students and undergraduates and $61 \%$ of post-graduates frequently exhibited academic procrastination behaviour.

Academic procrastination is a complex behaviour which is affected with time management, motivation, decision-making, perfectionism, irrational beliefs, personality traits, genetic traits, and other factors.

The study carried out with two undergraduate groups revealed that when qualified students (with higher achievement scores) were compared to unqualified students (with lower achievement scores), they exhibited frequent procrastination behaviour due to "the task causing a feeling of discomfort"; unqualified students procrastinated more frequently due to their fears of making mistakes and not being able to receive the approval of others (Ferrari et al, 1998). It was found in another study conducted that the undergraduate students who actively procrastinated had higher extrinsic motivation like parental concern and depending on this, their academic procrastination behaviour increased. On the other hand, students who passively procrastinated had higher levels of intrinsic motivation and their academic procrastination behaviour decreased based on it (Seo, 2013; Soysa \& Weiss, 2014).

Milgram and et al (1988) conducted a study on university students and they determined that tasks which were not fun and considered as challenging were postponed. Uzun Özer (2009) stated in her study that fear of making mistakes, laziness, and the difficulty of decisionmaking were important predictors of academic procrastination.

Many cognitive based educational programs have been tried to hinder academic procrastination behaviour and significant results have been obtained regarding preventing academic procrastination (Binder, 2000; Schubert et al, 2000; Ramsay, 2002; Horebeek et al, 2004; Kağan, 2010)

Ellis(1991), particularly, was very much affected by ancient philosophers such as Epictetus and Marcus Aurelius and formed rational emotive behaviour therapy approach (REBT) by applying $\mathrm{ABC}$ model on human disturbances. Ellis suggests that according to the $\mathrm{ABC}$ theory "A" is the events and conditions which activate men's goals and standards. Selection of reactions given in response to these conditions cause a series of emotional and behavioural consequences with which the individual is disturbed or undisturbed and this is defined as "C" in REBT. These consequences are shaped as a result of acceptance and effects of a series of beliefs (B). If these beliefs are rational and functional, this situation results in rationality and tendency to help oneself. On the contrary, if these beliefs are irrational and dysfunctional, their consequences might be destructive in terms of social and individual life.

As stated by McGINN (1997) Rational Emotive Behaviour Therapy (REBT) not only pays attention to mental retardation but also it is concerned about all cognitive, affective, and behavioural problems. 
A curriculum based on cognitive affective and behavioural approach was designed in this experimental study carried out on this basis and its effectiveness was tested on an experimental group.

\section{Problem Sentence}

What is the effect of rational emotive behavior based on academic procrastination prevention training programme?

\section{Method}

\section{The Research Design}

Pre-test post-test with control group experimental design was used in this research study. Experimental design was presented in Table 1.

Table 1.Experimental Design of the Research Study

\begin{tabular}{|c|c|c|c|c|}
\hline \multirow{4}{*}{ GROUPS } & Pre-Test & $\begin{array}{l}\text { Experiment } \\
\text { conditions }\end{array}$ & Post-test & Monitoring Test \\
\hline & Academic & Curriculum & Academic & Academic \\
\hline & Procrastination & & Procrastination & Procrastination \\
\hline & Scale & & Scale & Scale \\
\hline $\begin{array}{l}\text { Experimental } \\
\text { Group }\end{array}$ & $\mathrm{X}$ & $X$ & $\mathrm{X}$ & $\mathrm{X}$ \\
\hline Control Group & $\mathrm{X}$ & - & $X$ & $X$ \\
\hline
\end{tabular}

The research was carried out as a experimental study which included pre-test, posttest, monitoring test and a control group. In the research, a $2 \times 3$ randomized factorial was used. The first factor points to independent treatment groups (experimental, control) and the other factor shows the repeated measures related to a dependent variable (pre-test, post-test, monitoring test).

There is an independent and a dependent variable in the research model. The independent variable is the education program developed according to the rational emotive behaviour therapy approach. The dependent variable is the academic procrastination behaviours of the university students.

Analyzis of Nonparametric was used to determine whether there was a statistical difference between the average scores of academic procrastination of the students in the experimental and control groups in the study regarding the changes observed throughout the pre-test, post test and monitoring test measurements. The significance level is accepted to be 0,05 in the statistical analyses.

\section{Working Group}

The sampling of the research group was composed of the students chosen among the ones studying in Giresun University in 2012-2013 academic year and who volunteered to participate in the study.

The sample of the study included students whose academic procrastination tendency was ranked as moderate and high using an academic procrastination scale developed by Çakıc1(2003). The scale was administered with 130 university students and 70 personality whose scores were ranged between (19-44) in the scale were drummed out of the low procrastination group in the sampling group. Out of 60 students who completed the scales in 
full and whose academic procrastination tendency was moderate (45-70) and high (70-95), 30 of them were identified with random assignment method.

These students were assigned to experimental and control groups according to the scores they got from the academic procrastination scale. In addition to this, they were placed equally in the groups taking into consideration their genders and programs with the help of the personal information form designed by the researcher.

After constituting the groups, independent samples t-test was administered to compare whether the groups are equal to one another. t-test for unrelated samples is used to test whether the associated population means are significantly different (Büyüköztürk, 2014: 44)

Table 2. t-Test Results of the Groups Regarding Academic Procrastination Pre-test Scores

\begin{tabular}{lllllll}
\hline Groups & $\mathrm{N}$ & $\bar{x}$ & $\mathrm{SS}$ & $\mathrm{Sd}$ & $\mathrm{t}$ & $\mathrm{p}$ \\
\hline Experimental & 15 & 68.40 & 4.55 & 28 & 2.69 & .79 \\
Control & 15 & 68.93 & 6.19 & 28 & 2 \\
\hline
\end{tabular}
$\mathrm{p}<.05$

As a result of the analysis, it was found that there was not a significant difference between the groups' academic procrastination pre-test scores $(\mathrm{t}(28)=2.69 \mathrm{p}>.05$, Experimental group $(\bar{x}$ =68.40), Control group $(\bar{x}=68.93)$; therefore, the groups were equal.

The control group included four males and eight females and the experimental group was composed of five males and seven females. The average age of the participants in the experiment and control group was 20,25.

The scale was given as a pre-test to experimental and control groups. Academic procrastination prevention program based on rational emotive behaviour therapy approach designed by the researcher was administered to the experimental group in nine sessions. Nothing was done in the control group. After the experimental group implementations were finished, post test measurements were taken and monitoring measurements were taken 30 days after the ending of the experimental implementations.

Three subjects were drummed out of the experimental group due to their absenteeism. In order not to spoil the balance between the groups, three subjects chosen randomly and ranged between similar scores were also drummed out of the control group. As a result, both experimental and control groups were composed of twelve subjects and the statistical operations were performed via data gathered from these subjects.

\section{Data Collection Tools} study.

Demographic Information Sheet and Academic Procrastination Scale were used in the

\section{Demographic Information Sheet:}

This form included personal information such as gender, age, departments they are studying, grade level and academic performance. 


\section{Academic Procrastination Scale (APS):}

Academic Procrastination Scale was developed by Çakıc1 (2003). It consists of 19 items and items were scored using a 5-point Likert-type scale where 1 indicates the statement which contains academic procrastination like "It does not represent me" and 5 indicates agree with the item like "It completely represents me". The highest point one can get from the scale is 95 and the lowest score from the scale is 19. Cronbach's alpha coefficient of reliability was found to be .92 . Cronbach's alpha coefficient calculated for the first factor of the scale was .89 and .84 for the second factor of the scale. Spearman Brown split half reliability was found to be total $.85, .87$ for the 10 -item first half of the test and .86 for the $9-$ item second half of the test. Test-retest reliability coefficient calculated after administering the APS to 65 high school students with 17 day intervals was found to be .89 . The scale's test-retest reliability coefficient for the first factor was found to be .80 and .82 for the second factor (Çakıc1, 2003).

\section{Process}

During the development process of the program, national and international literature was scanned and the variables related to academic procrastination were tried to be determined.

Kutlesa(1998) conducted a study on university students and based on the evaluations of the students at the end of the sessions, he posited the factors necessary in a procrastination treatment program in the following order:

Self-acceptance, self-awarding and positive thinking, realizing the consequences of procrastination, identifying irrational beliefs, acquiring insights, analysis and defining sub goals.

During the scanning study, it was identified that time management skill, motivation, and irrational beliefs are important variables connected with academic procrastination behaviour.

In the first session of the program, information about procrastination-academic procrastination behaviour was given and the objectives which the subjects aim at realizing were tried to be defined.

In the second session, the relation between the academic procrastination behaviour, academic procrastination and automatic thoughts were studied.

In the third session, the $\mathrm{ABCs}$ of behaviour, importance of emotions in our academic life was undertaken. Information about rational emotive behaviour therapy approach and its fundamental concepts was given.

In the fourth session, negative basic beliefs, self-acceptance, and importance of having realistic expectations were discussed.

In the fifth session, effective decision making, and the obstacles to decision making and implementation were tackled.

In the sixth session, "rational beliefs" were discussed rather than "irrational beliefs" and an attempt was made to have the group members construct alternative rational beliefs. 
In the seventh session, effective time management and time traps were emphasized.

In the eighth session, taking responsibility and importance of making realistic choices were emphasized.

In the ninth session, the gains of the group members in the process were reviewed and the importance of sustainability of the gains was emphasized.

Group sessions were limited to 90 minutes. At the beginning of each session, students were informed about the session goals, sessions started with warm-up activities and motivation stories were told. At the end of sessions, the sessions were summarized and homework was assigned for the next session. When each session ended, group members were given a form to answer. The following are the questions which are asked to be answered.

- What have you realized about your opinions throughout the session?

- What have you realized about your feelings throughout the session?

- What have you realized about your behaviours throughout the session?

\section{Procedure}

\section{Data Analysis}

A "Mixed Design Analysis of Variance", a parametric model, was considered to determine whether there was a statistically significant difference regarding the scores the experimental and control groups got from the changes observed throughout the monitoring test and the hypotheses of this statistical model given below were tested:

(1) Sphericity must be obtained under the conditions where there are three or more levels of repeated measure (Büyüköztürk, 2014: 71).

(2) Dependent variable is on the lowest interval scale.

(3) Scores of the dependent variable exhibit normal distribution in each sub group.

(4) The variance of the groups' scores obtained at the same time is equal.

(5) The covariance is equal for the double combinations of measurement sets.

(6) The difference score calculated for any subject is independent of any difference scores calculated for the other subjects (Büyüköztürk, 2014: 79).

As a result of the statistical analysis, it was found that sphericity and normality of variances were not provided and the covariance matrices were not equal. Then, non-parametric model was utilized as statistical analysis.

Out of non-parametric tests, the Mann-Whitney U test and the Wilcoxon Signed Rank Test were administered with the intention of identifying whether there was a statistically significant difference regarding the changes observed throughout the evaluation of the pretest, post-test, and monitoring test scores of the experimental and control groups which they got from the Academic Procrastination Scale in the research study.

The Mann-Whitney $U$ test which tests whether there is a statistically significant degree of difference between the scores obtained from two unrelated samples was used to test whether the academic procrastination scores of an academic procrastination curriculum based on cognitive affective and behavioural approach changed with regard to the experimental and control groups (Büyüköztürk, 2014:165). The Wilcoxon Signed Rank Test used to test the 
significance of the differences between the scores belonging to two related samples was administered to determine whether there was a significant difference between the pre-test, post test, and monitoring test scores of the experimental group and the control group that participated in the training program (Büyüköztürk, 2014:174). The significance level in statistical analysis was accepted to be 0.05 .

\section{Findings}

This section will include the findings obtained from analysis performed depending on the hypotheses of the research.

The aim of this study is to examine the effect of the curriculum based on cognitive affective behavioural approach on university students' academic procrastination behaviour.

In the research study the effect of independent variable (Academic Procrastination Curriculum) on the dependent variable (academic procrastination behaviour) was examined.

\section{Qualitative Results}

This section consisted of qualitative findings obtained from the analysis based on the hypotheses of the research.

\section{What have you realized about your opinions throughout the session?}

Most of the students stated that they frequently used irrational beliefs in their daily and academic lives without realizing them. Moreover, most of the students identified that their cognitive distortions and irrational behaviours had negative effects on their academic performance. Nearly all of the students had the opinion of "maladaptive perfectionism". Again, most of them had the way of thinking such as "catastrophizing,- have to, must, and reading mind". Most of the students described their irrational beliefs as negative and unhealthy. On the other hand, they described the rational beliefs they developed throughout the sessions as positive and functional.

\section{What have you realized about your feelings throughout the session?}

The students stated that their opinions and beliefs affected their feelings over "ABC" model. Most of the students determined that their irrational beliefs most of the time led to emotions which were negative and non-functional. They also mentioned that the emotions caused by cognitive distortions and irrational beliefs were usually disturbing. The students particularly mentioned the emotion of remorse/regret they experienced as a result of academic procrastination behaviour. The male students generally experienced the emotions of anger and remorse and the female students usually experienced the emotions of embarrassment, guilt, and worthlessness.

Most of the students described their state of feelings caused by irrational beliefs as negative and unhealthy. These emotions mostly were the emotions like remorse, embarrassment, guilt, and worthlessness. On the other hand, they described their state of emotions caused by the rational beliefs they developed throughout the sessions as positive, healthy, and functional.

These states of feelings were sadness in place of embarrassment and remorse and being able to appraise oneself in place of grief and worthlessness 


\section{What have you realized about your behaviours throughout the session?}

The students stated that the result of their cognitive distortions and irrational beliefs led to academic procrastination behaviour. Most of the students had the habit of using time badly. Although some students decided not to procrastinate, they complained about falling back into procrastination cycle. One student stated that he felt himself unqualified about doing homework and added that until he started university, his family members did his homework and that's why he did not know how to do homework. Most of the students found their attitudes and habits which caused academic procrastination behaviour as negative and irritating. Most students stated that keeping journal homework assigned about academic procrastination behaviour in the forthcoming sessions was beneficial.

\section{Quantitative Results}

This section consisted of quantitative findings obtained from the analysis based on the hypotheses of the research.

The Mann-Whitney U test and the Wilcoxon Signed Rank Test were administered with the intention of identifying whether there was a statistically significant difference between the academic procrastination average scores of the students from the experimental and control groups regarding the changes observed throughout the pre-test, post-test, and monitoring test evaluations.

1) There is a significant difference in favour of the experimental group between the academic procrastination post-test total scores of the students in the experimental group and the control group post-test total scores.

2) There is a significant difference in favour of the experimental group between the experimental group academic procrastination monitoring test total scores and the control group monitoring test total scores

The findings related to the hypotheses of the research study were given in Table 3 .

Table 3. U Test Table for the Academic Procrastination Scores of Control and Experimental

\begin{tabular}{|c|c|c|c|c|c|c|}
\hline \multicolumn{7}{|c|}{ Group } \\
\hline Academic & & & Mean & Rank & $\mathrm{U}$ & $\mathrm{p}$ \\
\hline Procrastination & GROUP & $\mathrm{n}$ & Rank & Total & & \\
\hline \multirow[t]{3}{*}{ PRE-TEST } & EXPERIMENTAL & 12 & 12.67 & 152.00 & 70.00 & .908 \\
\hline & CONTROL & 12 & 12.33 & 148.00 & & \\
\hline & Total & 24 & & & & \\
\hline \multirow[t]{3}{*}{ POST TEST } & EXPERIMENTAL & 12 & 7.17 & 86.00 & 8.00 & $.000 * *$ \\
\hline & CONTROL & 12 & 17.83 & 214.00 & & \\
\hline & Total & 24 & & & & \\
\hline \multirow[t]{3}{*}{ MONITORINGTEST } & EXPERIMENTAL & 12 & 8.13 & 97.50 & 19.50 & $.002 *$ \\
\hline & CONTROL & 12 & 16.88 & 202.50 & & \\
\hline & Total & 24 & & & & \\
\hline
\end{tabular}

$* \mathrm{p}<0.005 ; * * \mathrm{p}<.001$

At the end of the experimental study consisting of nine sessions, a significant difference was found between the scores of experimental group and control group students who participated in the cognitive affective training program $\mathrm{U}=8.00, \mathrm{p}<.001$.

Considering the mean ranks, it was found that academic procrastination post-test total scores of the experimental group that participated in the training program were lower than the 
control group. Considering the scores of the monitoring test carried out a month after the sessions were completed, a significant difference was found between the academic procrastination scores of the experimental and control groups $U=19.50, p<.005$.

When the mean ranks were considered, it was understood that academic procrastination posttest total scores of the experimental group that participated in the training program were lower than the control group.

3. There is a significant difference between the academic procrastination pre-test total scores of the experimental group students and post-test total scores of the control group.

4. There is a significant difference between the academic procrastination post-test total scores of the experimental group students and monitoring test total scores of the experimental group.

The findings related to the hypotheses of the research study were given in Table 4 .

Table 4. Wilcoxon Signed Rank Test Analysis Table for the Experimental Group's Academic Procrastination Scores

\begin{tabular}{|c|c|c|c|c|c|c|}
\hline $\begin{array}{l}\text { Academic } \\
\text { Procrastination }\end{array}$ & & $\mathrm{n}$ & $\begin{array}{l}\text { Mean } \\
\text { Rank }\end{array}$ & $\begin{array}{l}\text { Rank } \\
\text { Total }\end{array}$ & $\mathrm{z}$ & $\mathrm{p}$ \\
\hline PRE-TEST- POST & Negative rank & 10 & 6.40 & 64.00 & 2.75 & $.006 *$ \\
\hline TEST & $\begin{array}{l}\text { Pozitive rank } \\
\text { Equal }\end{array}$ & $\begin{array}{l}1 \\
1\end{array}$ & 2.00 & 2.00 & & \\
\hline POST TEST- & Negative rank & 8 & 7.06 & 56.50 & 1.37 & .169 \\
\hline MONITORINGTEST & $\begin{array}{l}\text { Pozitive rank } \\
\text { Equal }\end{array}$ & $\begin{array}{l}4 \\
0 \\
\end{array}$ & 5.38 & 21.50 & & \\
\hline PRE-TEST- & Negative rank & 11 & 7.00 & 77.00 & 2.98 & $.003 * *$ \\
\hline MONITORINGTEST & $\begin{array}{l}\text { Pozitive rank } \\
\text { Equal }\end{array}$ & $\begin{array}{l}1 \\
0\end{array}$ & 1.00 & 1.00 & & \\
\hline
\end{tabular}

$* \mathrm{p}<0.01 ; * * \mathrm{p}<0.005$

The following values were obtained:

Pre-test mean rank.: 6.40; Post test mean rank.: $2.00(\mathrm{z}=2.75, \mathrm{p}<.05)$; Post test mean rank: 7.06; Monitoring test mean rank.: $5.38(\mathrm{z}=1.37, \mathrm{p}>.05)$; Pre-test mean rank.: 7.00; Monitoring test mean rank.: $1.00(\mathrm{z}=2.98 \mathrm{p}<.05)$

The analysis results demonstrate that there is a significant difference between the pre-test post test, post test-monitoring test, and pre-test- monitoring test scores of the experimental group students who participated in the study. This finding emphasizes that the cognitive affective behavioural training had positive effects on the experimental group.

5. There is not a significant difference between the academic procrastination pre-test total scores of the control group students and post-test total scores of the control group.

6. There is not a significant difference between the academic procrastination post-test total scores of the control group students and monitoring test total scores of the control group.

The findings related to the hypotheses of the research study were given in Table 5 . 
Table 5. Wilcoxon Signed Rank Test Analysis Table for the Control Group's Academic Procrastination Scores

\begin{tabular}{|c|c|c|c|c|c|c|}
\hline $\begin{array}{l}\text { Academic } \\
\text { Procrastination }\end{array}$ & & $\mathrm{n}$ & $\begin{array}{l}\text { Mean } \\
\text { Rank }\end{array}$ & $\begin{array}{l}\text { Rank } \\
\text { Total }\end{array}$ & $\mathrm{Z}$ & $\mathrm{p}$ \\
\hline PRE-TEST- POST & Negative rank & 5 & 6.70 & 33.50 & 0.43 & .665 \\
\hline TEST & $\begin{array}{l}\text { Pozitive rank } \\
\text { Equal }\end{array}$ & $\begin{array}{l}7 \\
0\end{array}$ & 6.36 & 44.50 & & \\
\hline $\begin{array}{l}\text { POST TEST- } \\
\text { MONITORINGTEST }\end{array}$ & $\begin{array}{l}\text { Negative rank } \\
\text { Pozitive rank } \\
\text { Equal }\end{array}$ & $\begin{array}{l}8 \\
3 \\
1\end{array}$ & $\begin{array}{l}6.38 \\
5.00\end{array}$ & $\begin{array}{l}51.00 \\
15.00\end{array}$ & 1.60 & .109 \\
\hline $\begin{array}{l}\text { PRE-TEST- } \\
\text { MONITORINGTEST }\end{array}$ & $\begin{array}{l}\text { Negative rank } \\
\text { Pozitive rank } \\
\text { Equal }\end{array}$ & $\begin{array}{l}7 \\
4 \\
1\end{array}$ & $\begin{array}{l}6.57 \\
5.00\end{array}$ & $\begin{array}{l}46.00 \\
20.00\end{array}$ & 1.15 & .247 \\
\hline
\end{tabular}

The following values were obtained:

Pre-test mean rank.: 6.70; Post test mean rank.: 6.36(z=0.43, $\mathrm{p}>.05)$; Post test mean rank: 6.38; Monitoring test mean rank.: $5.00(\mathrm{z}=1.60, \mathrm{p}>.05)$; Pre-test mean rank.: 6.57; Monitoring test mean rank.: $5.00(\mathrm{z}=1.15, \mathrm{p}>.05)$.

The analysis results demonstrate that there is not a significant difference between the pre-test post test, post test-monitoring test, and pre-test- monitoring test scores of the control group students who participated in the study.

\section{Discussion and Results}

The findings about the effects of academic procrastination training program based on cognitive affective behavioural approach intended to reduce the academic procrastination behaviours on university students' academic procrastination behaviour will be discussed in this section.

The experimental study carried out revealed that academic procrastination training program based on cognitive affective behavioural approach intended to reduce the academic procrastination behaviours had negative-positive effects on university students' academic procrastination behaviour.

In many cognitive -behavioural group experiences carried out in previous years (Binder, 2000; Schubert et al, 2000; Ramsay, 2002; Horebeek et al, 2004; Kağan, 2010), it was found that procrastination behaviours of the individuals who participated in group experiences based on cognitive -behavioural approach decreased significantly when compared to those who did not participate in them. A lot of variables which can cause procrastination behaviour such as cognitive distortions and irrational beliefs, motivation, and effective time management were discussed in these studies. Raising awareness about the procrastination behaviours of the individuals, their rational, realistic, and pragmatic choices regarding their preferences about effective time management and rational beliefs were eventually effective in reducing procrastination behaviour.

It was found with reference to similar principles in this study that academic procrastination training program based on cognitive affective behavioural approach which aims at reducing the academic procrastination behaviours was effective on university students' academic procrastination behaviour. 
Some recommendations about the implementations and the research studies which would be carried out in the future in accordance with the results of the research were presented below: This study has some limitations. This study was carried out with the student group studying in the Departments of Psychological Counselling and Guidance and Primary School Teaching in Education Faculty. A similar study can be carried out with similar groups from different populations in different departments of different faculties at different education levels. Academic procrastination behaviour consists of many complex cognitive, affective, and behavioural factors. Therefore, the curriculum implemented can be redesigned and enriched including conditions like time management, motivation, decision-making, self-respect, irrational beliefs, and affective intelligence.

The implemented "Academic Procrastination Training Program" can be developed in a way to include General Procrastination Behaviours and it can be implemented again.

\section{References}

Bandura, A.,(1986), Social Foundations Of Thought And Action: A Social Cognitive Theory, Prentice-Hall, $617 \mathrm{pp}$.

Bandura, A., Caprara, G. V., Barbaranelli, C., Gerbino, M., Pastorelli, C. (2003)., Role of Affective Self-Regulatory Efficacy in Diverse Spheres of Psychosocial Functioning, Child Development, 74(3), 769-782

Balk1s, M.,(2013), Academic Procrastination, Academic Life Satisfaction And Academic Achievement: The Mediation Role Of Rational Beliefs About Studying, Journal of Cognitive and Behavioral Psychotherapies, 13(1), 57-74.

Binder, K., (2000), The Effects of an Academic Procrastination Treatment on Student Procrastination and Subjective Well-Being, A thesis submitted to the Faculty of Graduate Studies and Research In Partial Fulfillment of The Requirements For The Degree of Master of Arts, Carleton University, Ottawa, Ontario

Büyüköztürk, Ş., (2014), Sosyal Bilimler İçin Veri Analizi El Kitabı[Data Analysis Handbook for Social Sciences], Extended 19th Edition, Ankara: Pegem Academi Publishing.

Çakıc1, D. Ç., (2003), An Examination of the general procrastination behavior and academic procrastination behavior in high-school and university students, Published Master Thesis. Ankara University, Institute of Education Sciences, Ankara

Duru, E. \& Balk1s,M.(2014), The Roles of Academic Procrastination Tendency on the Relationships among Self Doubt, Self Esteem and Academic Achievement, Education and Science, 39(173), 274-287

Dryden, W. (2000). Overcoming Procrastination(Ertelemek yaşamı kaçırmaktır) (çev. G. Günay). İstanbul: Rota Publishing.

Ellis, A., (1991), The ABCs of RET, The Humanist, 50th Anniversary, January/February 1991, 19-49

Ferrari, J. R., Keane, S. M., Wolfe, R. N., \& Beck, B. L. ,(1998), The Antecedents and Consequences of Academic Excuse-Making: Examining Individual Differences in Procrastination. Research in Higher Education, 39(2), 199-215. DOI:10.1023/A:1018768715586

Freud, S.(2013 Reprint of 1936 Edition), Inhibitions, Symptoms and Anxiety, Martino Publishing, 178 pp.

Horebeek, W. V., Michielsen, S., Neyskens, A., Depreeuw, E. In Henri C. Schouwenburg. (Ed); Lay, Clarry H. (Ed); Timothy A., Ph.D. Pychyl (Ed); Joseph R. Ferrari (Ed), (2004). Counseling the Procrastinator in Academic Settings. , (pp. 105-118). Washington, DC, US: American Psychological Association, xiii, 250 pp. 
Kağan, M., (2010), An evaluation the effectiveness of academic procrastination behavior preventation program based on rational emotive behavioral approach, Published Ph.D., Ankara University, Institute of Education Sciences, Ankara

Kim, R.K. \& Seo, E.H. (2015), The relationship between procrastination and academic performance: A meta-analysis, Personality and Individual Differences, 82, 26-33

Knaus, B., (2011), Beat Procrastination Now! (Online) http://rebtnetwork.org/l (03.10.2012)

Kutlesa, N., (1998), Effects of Group Counseling With University Students Who Complain of Procrastination. Unpublished MEd, The University of Western Ontario, Canada.

McGINN, L. K., (1997), Interview: Albert Ellis on Rational Emotive Behavior Therapy, American Journal of Psychotherapy, 51(3), 309-316

Milgram, N. A., Sroloff, B. \& Rosenbaum, M., (1988), The Procrastination of Everyday Life, Journal of Research In Personality, 22, 197-212

Ramsay, J.R., (2002), A Cognitive Therapy Approach for Treating Chronic Procrastination and Avoidance: Behavioral Activation Interventions, Journal of Group Psychotherapy, Psychodrama \& Sociometry (JGPPS), 55, 79-92

Seo, E.H.,(2013), A Comparison Of Active and Passive Procrastination In Relation to Academic Motivation, Social Behavior And Personality, 41(5), 777-786

Schubert W., Lilly, J., \& Stewart, D. W., (2000), Overcoming the Powerlessness of Procrastination, Guidance \& Counseling, 16(1), 39-43

Soysa, C.K. \& Weiss, A., (2014), Mediating perceived parenting styles-test anxiety relationships: Academic Procrastination and Maladaptive Perfectionism, Learning and Individual Differences, 34,77-85, DOI:10.1016/j.lindif.2014.05.004

Solomon, L. J. \& Rothblum, E. D., (1984), Academic Procrastination: Frequency and Cognitive- Behavioral Correlates, Journal of Counseling Psychology, 30(4), 503-509

Steel, P., (2007), The Nature of Procrastination: A Meta-Analytic and Theoretical Review of Quintessential Self-Regulatory Failure, Psychological Bulletin, 133(1), 65-94, DOI: 10.1037/0033-2909.133.1.65

Uzun Özer, B., (2009), Academic Procrastination in A Group of High School Students: Frequency, Possible Reasons and Role of Hope, Turkish Psychological Counseling \& Guidance Journal, 4(32), 18-19,

Uzun Özer, B., (2011), A Cross Sectional Study on Procrastination: Who Procrastinate More? 2011 International Conference on Education, Research and Innovation, IPEDR, 18, 34-37. (Online)http://www.ipedr.com, 04.06.2013

Van Der Kolk, B.A. (1987), Psychological Trauma, (pp. 105-117). Washington, DC, US: American Psychiatric Association Press, Inc.

Weinrach, S. G.,(1980), Unconventional Therapist: Albert Ellis, The Personnel and Guidance Journal, 59(3), 152-160, DOI: 10.1002/j.2164-4918.1980.tb00520.x 